\title{
Exploration on Training Methods of Undergraduates' Innovative Ability
}

\author{
Hui Tang ${ }^{1}$, Shanshan $\mathrm{HAO}^{1}$, Wenxue Wang ${ }^{1}$, Lei $\mathrm{Li}^{1}$, Baojun $\mathrm{Ge}^{1}$ \\ ${ }^{1-}$ School of Material Science and Engineering, Harbin University of Science and Technology, \\ Harbin 150080, China \\ Tanghui6003@sina.com
}

\begin{abstract}
To coordinate with the undergraduates' innovative experimental project hosted by the ministry of education and to direct at the characteristics of the students majored in non-metallic inorganic material, we use the opportunity and terrace of declaring the innovative experimental project "Effect of the mechanical property on bearing beams of three kinds of root-like reinforced concrete" to train the innovative thinking and innovative ability of three sophomores in seven aspects- scientific research investigation, establishment of project, science research ability and method, inquiry learning methods, practical ability, summary and publish of the results, spirit of teamwork. The essay mainly discusses the issues in three aspects, which are guiding ideology of undergraduates' innovative ability training methods, training category and methods and implementation effect, ect.
\end{abstract}

Keywords-innovative ability, practical ability, reform in education, undergraduate education

\section{INTRODUCTION}

In 2007, the ministry of education, the ministry of finance jointly started "the project of teaching quality and reform of undergraduates' education in colleges and universities" [1], and established national undergraduates' innovative experimental project. The project team composited by outstanding student for innovative research are supported, the university students' independent innovation interest and ability training are promoted, and amount of funds as a support platform are invested by implementing of the undergraduates' innovative experimental project plan. In 2007, ten colleges and universities implemented national undergraduates' innovative training plan. Under this background, the national universities successively formulated the undergraduates' scientific research training plan, aiming at cultivating the undergraduates' rigorous scientific attitude, innovative thinking consciousness, inquiry learning methods, practical ability and team spirit, and improving undergraduates' scientific research, innovation and practical ability[2-3]. A national undergraduates' innovative experimental project "Effect of the mechanical property of bearing beams for three kinds of root-like reinforced concrete" was declared by teachers who are related with course design team of non-metallic inorganic material major in our school. Three students participated in the project have achieved training and improvement in many aspects and the teacher has also accumulated some experience in this process, after more than one-year-training.

\section{GUIDING IDEOLOGY OF INNOVATIVE ABILITY TRAINING METHODS}

The state established the undergraduates' innovative experimental project aiming at developing and training undergraduates' innovation consciousness and ability, breaking the traditional higher education mode. We must fully realize that "innovation is the center, training is the goal, innovation can't apart from practice, and practice is the source of innovation”. The implementation and completion of the innovative experimental project can not be isolated, the two should be throughout the whole process of the entire university education and be associated with other teaching aspects. Only when the students' scientific research quality, innovation consciousness, learning methods, practical ability, innovation perseverance, and the spirit of cooperation have been thoroughly trained, can we get the final success. Therefore, the cultivation of college students' innovative ability should be based on training, and focus on the process. The training not only emphasize the development of skills and methods, but also emphasize methods and spiritual training. At the same time, with the rapid development of science and technology, more innovation ability training comes from interdisciplinary fusion and cross, and from the cultivation of composite talents with interdisciplinary knowledge structure, but not exist only in this field and this discipline any more. The success of the innovation project training would have an important demonstration effect and a profound influence on training mode of modern university undergraduate. So, students who participated in training program were required to have enough mental preparation and sense of responsibility. Both students and teachers who participated in the activities must have enough energy and enthusiasm, and actively devote themselves into research work.

\section{INNOVATIVE ABILITY TRAINING CATEGORY AND METHODS}

As the training object is students who have never engaged in innovative research, training category should include processes, which are systematic and integrated, such as scientific research investigation, establishment of project, inquiry learning methods, research ability and method, practical ability, corresponding research results summary and publish, etc.

\section{A. The training method of scientific research investigation}

The training method of scientific research investigation is divided into two aspects. 
(a) One is on-the-spot investigation, which is the training of the observation ability required in innovation. Observation is the primary stage of perceptual knowledge, and is also the perceptive process of active understanding. Without observation ability, there wouldn't be further memory and imagination, and the leap from perceptual knowledge to rational knowledge wouldn't be realized either[4]. In the early stage of establishment of project, students who participated in the project are directed to the construction site around school for on-the-spot investigation to learn about the situation, such as the existing problems of reinforced concrete structure designing technology and construction technology in nowadays construction industry, which is called finding out problems. We inspire students to solve the existing problem with advanced professional knowledge learned in the class, which is called solving problems. We hope that a kind of innovative ideas and innovative desire could form in students' mind, in such a process, and students' innovation observation, the innovation concept and innovation desire would be trained. The development of innovation ability and the formation of innovation behavior are based on the innovation concept and innovation desire.

(b) The other is to make use of modern network technology and the large amount of books and datas in the school library. By consulting a large number of professional books and literatures on architecture, mastering the development level and research status of reinforced concrete structure design technology and the research focus in this field, learning relevant knowledge on earthquake and building seismic technology, and understanding the current research situation, research direction of the project establishment is determined. Through this link, students' interest in innovation and screening ability on consulting literatures and summarizing ability is cultivated.

\section{B. The training method of scientific research establishment of project,}

By doing a lot of research investigation work, students have grasped the situation of project establishment. Then they are guided to read the relevant professional books steadfastly, after which they would have a clear understand of professional knowledge about the project, including basic theory, basic formula, feasibility analysis in theory and practice, etc. When the above issues would have been solved, we could begin the training of filling project declaration forms. In this link, students' innovative thinking ability, which refers to a thinking process of inventing or finding a new way to deal with something[5], is mainly trained. Rich imagination and intuitive understanding, deep mathematical ability are trained respectively, and students' autonomous learning and research learning methods at the same time.

Science is inherited, and innovation is based on the previous work. Devoting new ideas and new methods into the previous work and research further is the innovation.
Therefore, we guide students to take a broad view of the world, to learn the latest achievements in and abroad so that to make their own scientific research programs stand on a higher starting point.

\section{The training method of inquiry learning}

Students' autonomous learning and research learning are stressed on in the process of filling in project declaration training s. Such as: guiding the students to study the cement matrix composites in "the introduction to composite materials" and the basic theory of metal material fracture in "Metal Materials Academics" and "Seismic force theory", "Earthquake Engineering and Structural Dynamics" , independently. So as to make the cause of the earthquake and the reason of the building collapsed in the earthquake clearly, and the theory mechanism of the improvement of root-like reinforced concrete seismic capability is inferred in the project. Learning like this, they can apply what they have learned and enhance the confidence in scientific research, which is also an effective way to help students understand the self-value. This makes their attitude and behavior of initiative learning change actively, at the same time, the way of study with problems also effectively promotes the implementation of research learning methods.

\section{$D$. The training method of science research ability}

Engaged in the training of scientific research ability, we must pay special attention to cultivate the students' innovative thought. But what is innovation, Innovation is not unconventional, as unconventional issues are impossible to get a real innovation. The innovation is to find and solve conflicts based on our long and deep scientific practice. In the scientific research ability training, the most often encounter is math problems, as mathematics is a tool. When students have basic mathematical foundation and broad knowledge of the mathematics, knowledge of the theoretical concept included in the project comes first. The students should be trained to figure out the key impact of problems before carrying out research. To find new means to solve the problem, specific training includes certain of the research content, experimental plan formulation, the select of research method, product preparation process and the evaluation of experimental results, etc.

In scientific research process, it is not difficult to find some philosophical concepts, such as the concept of overall, the whole and local relations, the concept of development, and the concept of conflict. These are the basic ideas of philosophy, but very practical when used in scientific research. So, this link can guide students to learn more about philosophical concepts, which help students to discover and solve the problems easily, and make science research ability go step further.

\section{E. The training method of practical ability}

Practice ability is defined as students utilize 
knowledge and skills to solve the problems in the project. It directly plays a stable regulation controlling part in solving the problem of the process and the method for each individual. It is a complicated and unified physical and mental energy system, and contains four basic elements: practice motivation, general practice ability factor, special practice ability factors and situational practice ability factor [6]. Students' practical ability training should be based on the structure of the practice ability.

Practice ability is an important part of innovation ability, as innovation without practicability just talks. The training of innovation spirit and practice ability must be based on knowledge, and students' correct view is difficult to form without knowledge. There is no basis for analysis, and it is more difficult to innovate without basis for analysis. So, in order to train practice ability, we should train students' learning methods and attitudes at first and then train students' practice ability in the process of preparing root-like reinforced concrete. All the parts are completed by students independently, including determination of the theoretical calculation, procurement of raw materials, preparation of the templates and steel skeleton, preparation of roots-like reinforced concrete, sample performance test, the data collection and analysis and a series of process. For instance, when analyzing the experiment data, we found that conflict exists between theory and practice in certain sample test results-the actual test data and the theoretical analysis results has a big gap. At this time, we should warn students to practice first. As long as the date is real but not imaginary, it has credibility. When theory and practice is not consistent, we should consider modifying theory instead of modifying the experimental results.

In this link, teachers should pay special attention to train students' innovation perseverance and self-reliance spirit. Perseverance is a mental process that human consciously identify goals, according to which they control and adjust their action, overcome various difficulties, insist to realize their own goals, and it is the concentrated reflection of initiative and individual enthusiasm[7]. Although the students in the implementation process have been already aware of the importance of perseverance, the phenomenon lacking of perseverance still appears in the practical work..

Owing to too much care from parents and society, contemporary students have developed a habit of relying on others intensively, which leading students lack of the spirit of self-improvement and self-reliance. They are often standstill when facing setbacks. Their psychological endurance is insufficient, and the ability of self-determination is poor when facing problems. The above phenomena are not good for college students' innovative ability training, and these phenomena have appeared in the early days of our subject. According to this phenomenon, we adopted pressure force method, in which students were forced to the impasse. The task assigned to each student must be finished within the deadline, and the formation of each task was designed for different people. It is designed corresponding to students' weakness. For example, one student has an introverted personality, we would assign him a task contacting to the outside, such as purchasing raw materials or contacting processing or testing. In the process, he must work with people, so that his communicative ability is trained. For another example, we assign a student whose expression is very poor to perform as speaker in interim progress inspection, by which his ability of expression and improvisation is improved. This implementation has a good effect.

\section{F. The training method of results summary and publish} corresponding research results

We also train students' ability of writing academic papers on the basis of summarizing. It is required that every student must complete an academic paper, and the task has been satisfactorily completed. Each students has written an article, two of which have been accepted by the key magazine of China technology, and one is in proceeding. Although guiding teachers are very hard, their fatigue is swept away when they see the smiling faces because of the achievements.

\section{G. The training method of team spirit}

Team spirit is presented by ideas of overall situation, cooperation spirit and individual spirit of service. Team spirit is the basis of respect for personal interests and achievements. The core is collaboration, and the highest state is the centripetal force and cohesive force of all the members. Team work reflects the unification of individual interests and overall interests, and ensures the whole work of high efficiency operation[8]. The formation of team spirit is not at the cost of self-sacrifice. On the contrary, scattering the personality and performance specialty can ensure members to complete the task, and right collaboration willing and approach can produce real inner power, so that the task can be fulfilled better. The art of teamwork ability is trained in this link, and students are made to realize that real achievements can be achieved only by corporate effort in nowaday' scientific research.

\section{IMPLEMENTATION EFFECT OF INNOVATION ABILITY TRAINING METHODS}

Students who participated in national undergraduates' innovation experimental project are comprehensively cultivated on innovation ability in seven aspects. The training method is comprehensive, and it is a training mode conductive to students to become talents. In innovation ability training process, teachers need to make a series of judgments and decisions based on students' performance in order to adjust training program and improve the training methods constantly, and they also need to have a deep and comprehensive acquaintance of students' interest, ability, attitude, values and academic potential. Students fully understand and accept this approach as it is practical, 
advanced and scientific. For students, they not only exercise the ability but also gain the knowledge. This training mode can be used as reference, and has good operability.

\section{CONCLUSION}

To improve the teaching quality of colleges and universities, overcome the deficiency of current talent training mode, and emphasize the training of practical and innovative talent, the implementation of national undergraduates' innovative experimental project is very necessary. We must make full use of the good opportunity of college students' innovative training to establish new undergraduate talents' training mode. New talents' training mode should organically combine with undergraduates' innovative experimental project and other teaching links. As a mainline throughout the whole process of undergraduate education, putting it this way, not only can change the education concept of the higher education, manage the existing teaching resources, deepen the relationship of teachers and students, but also can deepen the reform of the educational mode without the increase of teaching links.

\section{ACKNOWLEDGMENT}

This work was Supported in part by Key Project of Higher Education Teaching Reform of Heilongjiang Province 2011(201105) and Special Project of Higher Education Teaching Reform of Higher Education Teaching Association China 2011 (2011HYZX021) and Special Project of Higher Education Comprehensive Reform of Heilongjiang Province..

\section{REFERENCES}

[1]The ministry of education, The ministry of finance. Suggestions on the Implementation of Teaching Quality and Reform of Undergraduate' Education in Colleges and Universities [Z].2007.1.22

[2] ZHANG Jiadong, FANG Hairong. Strengthening the Open Experimental Platform Building, Promoting Student Innovation Ability Training [J]. Modern Educational Technology, 2009(07).

[3]SUN Dongqing. Research on the Cultivation of Innovative Ability of Contemporary Undergraduates [J]. Henan Education, 2007(06).

[4]JIAO Yanchun. How to Cultivate the Observation Quality of Innovation[J]. Biology Teaching, 2001, 26(9).

[5] LI Qian. Innovation Thinking[J]. Journal of Dalian Official, 2005, 21(5):34-37.

[6] LI Lei, FU Weili. the Meaning, Structure and Cultivation Measures of Practice Ability [J]. Education Science, 2005, 21(2)

[7] XIN Zhipeng. the Essay on Personality Cultivation[EB/OL].<http://yx.lnsts.com/gexingxiuyang9.htm1999-1-19>

[8] Guangdong Association for Science and Technology. What is team spirit [EB/OL]. < http://www.sta.gd.cn/default.aspx.2007-10-10> 